The Notes and Comments section of the Fall 1985 issue of the Slavic Review generated the following comments and responses.

\title{
To THE EDITOR
}

Since I am quoted more than once in your current controversy about Soviet population losses, may I offer some comments.

I am not concerned to defend Rosefielde, some of whose argument, indeed, I find hard to follow. For, like most of your readers, I am not a demographer. But we laymen need not be buffaloed by the pyrotechnics of tables and equations offered us by Wheatcroft, Anderson, and Silver. They have computational skills the rest of us do not, but these give no validation whatever to their results since, as has been said of the finest computer, "rubbish in, rubbish out." The results depend, as you say in your editorial note, on the assumptions. Moreover, since demographers of the highest repute, like Feshbach and Bernstam, generally agree with my estimates, arithmetical skill as such is clearly not the point.

First, Anderson and Silver, apparently in accord with a recent revisionist notion that official evidence is best, criticize me for a "global characterization of the quality of" the 1939 "census" as a fake. Of course it is a fake. They argue that all censuses are imperfect, citing that of 1926. Of course all censuses are faulty, and that of 1926 (like most peacetime censuses) is usually estimated as being on the low side, by about 1.2 million to 1.5 million (which, incidentally, means that in using it as a base I and others proportionately underestimate the 1926-1937 death roll). But that other censuses are faulty has no bearing on the question of whether that of 1939 was faked. Here no ciphering will help: it is a matter of simple common sense. The 1937 census was suppressed and the census takers denounced as "a serpent's nest of traitors" (Bolshevik, no.23-24, 1938), and their crime was specifically referred to at the very time of the 1939 "census" as that of having "exerted themselves to diminish the numbers of the population of the Soviet Union" (Pravda, 17 January 1939). It thus requires unlimited naiveté to attach any credence whatever to the figures produced by their successors. If, as may be true, they are only wrong by two or three million, that is an interesting fact, like a forged check being only for a hundred rather than a thousand dollars, but it does nothing to validate them and, moreover, can only be deduced from other figures. It is at least encouraging that serious Soviet researchers seldom use figures from 1939.

On a minor, though simple, point Anderson and Silver also go wrong. "A population total of 156 million [in 1937] has sometimes been used by Conquest and Rosefielde." Not by me. I quote an even lower figure in The Great Terror, as a camp rumor, but I do not accept it or "use" it. I take it one is similarly allowed to quote Rosefielde, or AntonovOvseenko, and I intend to do so in the future, but I do not see the figure as in any way validated and so do not accept or "use" it-relying, rather, on the more established 164 million of the 1937 census. I think an unwary student might be misled by my critics' phraseology into thinking that I did, rather than did not, rely on the 156 million figure. If, however, Rosefielde is seeking a-speculative-support for the figure of 156 million, it is perhaps worth noting that the head of the Census Board in Khrushchev's time referred to the 164 million figure as the result "after adjustment" of the 1937 census: and an "adjustment" of 5 percent on 156 million plus would serve exactly; nor would an exaggeration on that scale be rare in even the most moderate Stalinist statistics.

But the gravest, indeed fundamental, fault in the Anderson and Silver paper is that they apply to the Soviet Union a set of population models that are derived and generalized from other countries with totally different demographic histories and, thus, are quite 
inapplicable. (Indeed, I believe that these tables have been tested by using them to attempt to deduce even the 1959 figures from those of 1970, and vice versa, without success.) In any case, the whole "assumption" behind their analysis collapses, and their conclusions are therefore wholly worthless.

The reason for such fiascos is plain. As Anderson and Silver remark, their approach shuns "the credibility of individual informants and observers and the logic of assembling evidence from disparate and often obscure sources." It does not seem to occur to them that the investigation of obscure events, in which the official facts and figures are notoriously false, requires the assessment-at any rate not mass rejection-of other evidence. This aberration is also to be found in current "revisionist" writing in other fields, concerned to prove that not much of a terror ever took place or that the peasants were happy as kings in the early 1930s (as against, e.g., Boris Pasternak's personal experience in the countryside of "inhuman, unimaginable misery").

Anderson and Silver reject my, and accept Wheatcroft's, views on labor camp numbers. They do not say why, but it is evidently because they reject, as he does, any merely empirical evidence that conflicts with the statistics-shuffling world of abstractions in which their thinking takes place. In the recent controversy in Soviet Studies I raised three testimonies that seemed to me to destroy Wheatcroft's (and of course Anderson's and Silver's) argument.

First, there is excellent evidence about the numbers arrested in 1937 and 1938 . The physicist Weissberg, who was in jail for over a year, tells how it was possible to estimate the intake from his own prison's catchment area by (for example) checking the numbers on the receipts for personal effects given by the NKVD. This number was compared with figures similarly arrived at by prisoners transferred from other areas of the USSR. The figure "varied between 5.5 and 6 percent of the total population." (Similar figures are reported by others.) These researches were done by men of the highest intellectual capacity, with little else to occupy their time, over a long period, and with considerable resources ("every cell possesses at least one statistician," $A$ World Apart by Gustav Herling [New York, 1951], p. 8). Why they should be dismissed out of hand is a psychological mystery.

Wheatcroft, at least, in the Soviet Studies controversy, tried to cope: the NKVD had (he suggested) known of such estimates and tried to baffle them by confusing the numeration of the receipts and so forth. This is a purely ad hoc argument. No evidence of anything like it is forthcoming, no way in which it could avoid detection is suggested, no plausible motive is advanced, and it is not explained why the NKVD should wish to exaggerate their haul (for such is the implication). Moreover, it is clear that the NKVD did not bother to see that prisoners did not have access to all sorts of secrets-for example, from prominent victims who were seldom segregated from the others.

This extremely weak retort of Wheatcroft's is better than his absence of retort to two other empirical testimonies: first, the 9,000 bodies of victims from 1937-1938 actually found executed in Vinnitsa. I noted in The Great Terror, Appendix A, that (if these were the only executions in the whole province) to apply this figure to the whole USSR would mean about 1.5 million executions in all: in fact I was underestimating, as though just over 9,000 bodies were dug up; there were a number of mass graves not excavated, and the full total was estimated at 12,000 to 15,000 . Applied to the USSR as a whole, 12,000 would mean about 2 million executions. Even if we assume that the execution rate in Vinnitsa, as a border province, was exceptionally high, it is obviously hard to bring that figure below a million. (And let us note, incidentally, that of the corpses identified about 60 percent were peasants and many others minor employees: which in itself makes nonsense of the theory that victims of the purge were predominantly party officials.)

Then, no reply has been made to Andrei Sakharov's flat statement that about 600,000 party members were shot (and another 550,000 died in camps). Sakharov, when in favor, had access to the highest political circles and is clearly not making a guess. His party 
execution figure, when we consider the peasant, and other, dead of Vinnitsa, must certainly be supplemented by a large number of nonparty dead, and a grand total of a million seems low. It has been reasonably established (both in general reporting and from an analysis, in Zbigniew K. Brzezinski, The Permanent Purge [p. 108], of 471 arrests of family members reported by 2,725 Soviet citizens, which recorded 52 known death sentences) that the proportion of death to labor camp sentences was about 10 percent. This finding would imply up to 10 million arrests, with 9 million going to camp. These figures and deductions are at least more solid than those bombinating in a vacuum and cannot be dismissed in the revisionist fashion.

It should be added of Wheatcroft's arguments in your pages that he does not here deal with Gosplan's figure for the Second Five Year Plan of a population of 180.7 million for 1938 (i.e. about 177.7 million for 1937), as against the (suppressed) 1937 census figure of 163.7 million: a deficit of 14 million. If we allow 2.5 million for unborn children-the equivalent of no births at all among 10 million "kulaks" for two years, and none for six months in the rural Ukraine-we are left with 11.5 million excess deaths for 1930 to 1937. But Wheatcroft slips over the whole question of Gosplan's, and similar, predictions by saying that, like other "plan" figures, they were exaggerated. But this statement assimilates two quite different things. Production figures were instructions to the country. Population figures were merely projections (the government issued no decrees relevant to population increase until 1936). The Gosplan figures-a good deal lower than those of earlier Soviet estimates-were in good accord with the natural population growth rate, if unimpeded by Terror, of what the population should have been. At any rate they cannot be dismissed by confusion with quite a different matter.

Finally, we are told that those who believe the Terror to have been more pervasive and casualties larger than historical or demographic revisionists believe are (as Wheatcroft here suggests) the products merely of "emotion." But, if we descend to this level, it is easy to find emotional, or temperamental, motives for underestimating such figures: First, the urge to novelty. Second, a parochial inability to assimilate facts that seem improbable to a desk-bound westerner. Nor is it true incidentally (as Wheatcroft implies) that a lower figure of a few million for the famine is just as unacceptable to Stalinist apologetics as the larger one. Even in 1933, when the official story was that there was no famine at all, they were happy with Walter Duranty reporting some 2 million excess deaths, the minimum that had any chance of acceptance outside party circles. (Duranty privately spoke of a population decrease, in 1932 and 1933, of 7 million to 8 million, adding that 10 million was "quite possible.")

I only make this point to rebut a disreputable imputation, all the less tolerable because Wheatcroft and others do not answer, or answer absurdly, the strongest evidence for high figures of both death and imprisonment. Surely whatever their conclusions, we should be able to take for granted of all serious historians of the period an acceptance of Edward Gibbon's statement, "Although I should not be ashamed to undertake the apology of Nero or Domitian, if I thought them innocent of any particular crime with which zeal or malice had unjustly branded their memory; yet I should indeed blush, if, in favour of tyranny, or even in favour of virtue, I had suppressed the truth and evidence of historical facts." On the substantial issue, one must, however, insist that the question of higher or lower estimates is an important one. (There are, of course, even higher estimates than I have put forward, and I have always made it clear that I regard mine as conservative, having almost always used the lower available figure compatible with acceptable evidence.)

As Wheatcroft says, it is true or nearly true that there is little moral difference between killing a few million people and a few tens of millions. But the difference is, nevertheless, historically and socially important. The effects on France, England, and Germany of World War I would have been far different if the casualties had been a third or a quarter what they really were. Similarly a death roll for the terror of the Stalin period 
in the tens of millions, with most families providing a victim, must mean a far more devastating psychological blow at the population than the smaller figure-quantity, as we are told, can change into quality. So the research is very far from being without significance.

ROBERT CONQUEST

Hoover Institution, Stanford University

\section{To THE EDITOR:}

For his own polemical purposes, Stephen G. Wheatcroft has suddenly dragged me into his long-running dispute with Steven Rosefielde over the number of unnatural deaths under Stalin's rule. Wheatcroft uses me as an example of western scholars who wrongly and "uncritically" accept high figures. He writes: "Stephen Cohen has twice recently cited Conquest, Antonov-Ovseenko, Maksudov, Diadkin, and Kurganov as authorities for the statement that ' 20 million is a conservative estimate' for the number of excess deaths under Stalin before 1929."

Wheatcroft misrepresents me in three ways. First, I wrote the passage to which he refers only once, not twice-in my essay "The Stalin Question Since Stalin"; the other source he gives is actually an abridged reprint of that essay. Second, he distorts what I wrote, which was this: "No one has yet managed to calculate the exact number of deaths under Stalin. Among those who have tried, twenty million is a conservative estimate." Both sentences accurately report the state of scholarship when I was writing (1981), and both are more tentative than Wheatcroft leads readers to think. Third, the figure I gave did not refer to the period "before 1929," as Wheatcroft claims, but to deaths that resulted from collectivization and police terror, particularly from 1929 to 1939.

I lack sufficient expertise to decide who is closer to the historical truth in this dispute, Wheatcroft or Rosefielde. But in trying to evaluate their rival assertions, can I assume that Wheatcroft is more careful with his demographic data than he was with my two sentences?

Stephen F. Cohen

Princeton University

\section{To THE EDITOR,}

I regret that Stephen Cohen has made the accusation that I dragged him into my dispute with Steven Rosefielde for my own polemical purpose. The reason that I mentioned Stephen Cohen was simply as an example of what I considered to be an incorrect assessment of the state of western scholarship over evaluations of the scale of excess mortality (above some, usually undefined, normal level) under Stalin. I was disturbed that Stephen Cohen and others were beginning to accept that western scholarship regarded 20 million as a conservative estimate of excess deaths under Stalin before 1939.

I did not attempt to analyse Stephen Cohen's statements in detail because they did not appear to warrant it. They used a popular but rather imprecise and inaccurate expression. No one was claiming to calculate an "exact number" as Cohen suggests and Cohen's reference to "deaths under Stalin" presumably was meant to refer to some kind of measure of excess mortality. (I assume that Cohen was not holding Stalin responsible for the Russian population not being immortal!)

The important thing for me was to correct what I considered to be an incorrect, selective historiography of the problem. By restricting his survey to Conquest, Antonov- 